\title{
MANAJEMEN RISIKO BENCANA HIDROKLIMATOLOGI UNTUK KETAHANAN KOTA DI SEMARANG
}

\author{
Nina Awalia Safitri* \\ *Postgraduate School, Universitas Airlangga \\ Email: nina.awalia.safitri-2018@pasca.unair.ac.id
}

\begin{abstract}
Abstrak
Kota menghadapi semakin banyak kesulitan dan tantangan global abad ke-21. Dari efek perubahan iklim, pertumbuhan populasi migran, infrastruktur yang tidak memadai, serangan dunia maya dan pandemic. Selain tekanan kronis dari masalah yang ada, ketika bencana terjadi, daerah perkotaan yang terletak dipesisir dan populasinya juga lebih rentan terhadap guncangan yang menyebabkan peningkatan kerentanan, ketidakpastian, dan dampak ganda risiko kota. Kekhawatiran kota Semarang yang paling mendesak adalah tentang air, dalam RTRW 2011-2031, Kota Semarang yang merupakan daerah rawan bencana seperti daerah rawan rob, banjir, longsor dan rentan terhadap gerakan tanah. Masalah sosial juga mulai meningkat di kota karena meningkatnya tekanan ekologis. Dalam beberapa tahun terakhir, dampak dari banjir berlipat ganda karena naiknya permukaan laut, erosi pantai, dan penurunan muka tanah. Transformasi fisik yang cepat menimbulkan banyak tantangan termasuk urbanisasi dan penyebaran yang cepat dan tekanan regional yang kompleks. Dengan Menggunakan metode penelitian kualitatif dan pendekatan studi kasus. Kenyataan pahit diatas perlu adanya kajian manajemen risiko bencana untuk mengatasi masalah tersebut. Penelitian ini merupakan kumpulan strategi aksi kota mengelola risiko dari dampak perubahan iklim. penjabaran rencana aksi tersebut berkontribusi untuk meningkatkan ketahanan kota. Hasil penelitian ini mengungkap bahwa manajemen risiko yang dilakukan Kota Semarang sudah mengarah pada mitigasi dan upaya mereduksi risiko bencana hidroklimatologi meskipun upaya-upaya lainya harus tetap dioptimalkan.
\end{abstract}

Kata Kunci: bencana hidroklimatologi, ketahanan kota, manajemen risiko.

\begin{abstract}
Cities are facing increasingly global difficulties and challenges of the 21 st century. From the effects of climate change, migrant population growth, inadequate infrastructure, cyber-attacks, and pandemics. Apart from the chronic stresses of existing problems, when a disaster occurs, coastal urban areas and their populations are also more vulnerable to shocks that cause increased vulnerability, uncertainty, and the dual impact of city risks. The most pressing concern for the city of Semarang is about water, in the spatial planning and territory 2011-2031 by the city of Semarang is a disaster-prone area such as areas prone to tides, floods, landslides, and prone to ground movement. Social problems are also starting to increase in the city due to increasing ecological pressures. In recent years, the impact of floods has multiplied due to sea-level rise, coastal erosion, and land subsidence. The rapid physical transformation poses many challenges including rapid urbanization and spread and complex regional pressures. By using qualitative research methods and a case study approach. The harsh reality above requires a disaster risk management study to overcome this problem. This research is a collection of urban action strategies to manage risks from the impacts of climate change. the elaboration of the action plan contributes to increasing the resilience of the city. The results of this study reveal that the risk management carried out by the city of Semarang has led to mitigation and efforts to reduce the risk of hydro-climatological disasters, although other efforts must be optimized.
\end{abstract}

Keywords: hidroclimatological disaster, risk management, resilient city

\section{PENDAHULUAN}

Kota-kota menghadapi semakin banyak kesulitan dan tantangan global abad ke-21(Lal et al., 2011). Dari efek perubahan iklim, pertumbuhan populasi migran, infrastruktur yang tidak memadai, serangan dunia maya dan pandemi (IOM, 2020). Selain tekanan kronis dari masalah yang ada, ketika bencana terjadi, daerah perkotaan dan populasinya juga lebih rentan terhadap guncangan, yang menyebabkan peningkatan kerentanan, ketidakpastian, dan risiko kota (Narieswari et al., 2019). Kota-kota di Asia 
(C) (2021) Sekolah Pascasarjana Universitas Airlangga, Indonesia

termasuk yang paling rentan terhadap dampak perubahan iklim, seperti angin topan, gelombang badai, dan gelombang panas (Hijioka et al., 2014). Sayangnya, kotakmota ini juga menderita tekanan kronis seperti kemacetan lalu lintas, polusi, banjir, dan sampah yang tidak terkumpul (Bauer, 2014).

Adanya fenomena perubahan iklim yang meningkatkan kejadian bencana, berpotensi memperburuk tekanan (stresses), dan menciptakan guncangan (shocks) baru pada wilayah perkotaan (Wilson \& Arvanitakis, 2019). Data Informasi Bencana Indonesia (DIBI) menunjukan kejadian bencana di Indonesia masih didominasi oleh bencana hidroklimatologi, yakni bencana yang diakibatkan oleh iklim dan cuaca seperti banjir, tanah longsor dan putting beliung. Kejadian banjir mencapai 9.053 kasus. Puting beliung dengan jumlah 6.318 kasus dan tanah longsor dengan 5.130 kasus. Total seluruh kejadian bencana sejumlah

26.760 kasus. Diprediksi akan terus meningkat jumlahnya di masa depan (BNPB, 2018).

Kekhawatiran kota yang paling mendesak adalah tentang air, seperti disebutkan dalam RTRW 2011-2031, Kota Semarang memiliki daerah rawan bencana terdiri dari daerah rawan rob, daerah rawan banjir, rawan longsor dan rentan terhadap gerakan tanah (Bappeda Kota Semarang, 2011). Hingga Maret 2020, BPBD mencatat, setidaknya sudah ada puluhan kejadian bencana tanah longsor. Dengan rincian bulan Januari 35 kejadian, Februari 34 kejadian, dan Maret 22 kejadian tanah longsor. Total hingga tanggal 18 Maret 2020, BPBD Kota Semarang sudah mencatat 91 kejadian Tanah Longsor di Semarang. Dari data tersebut, tidak tercatat korban jiwa dalam kejadian sejumlah tanah longsor. Namun, beberapa kejadian longsor menyebabkan kerugian materiil (BPBD Kota Semarang, 2020).

Selain banjir, masalah sosial juga mulai meningkat di kota karena meningkatnya tekanan ekologis (Roberts \& Yano, 2010). Dalam beberapa tahun terakhir, dampak dari banjir berlipat ganda karena naiknya permukaan laut, erosi pantai, dan penurunan muka tanah (Akbar et al., 2019). Transformasi fisik yang cepat menimbulkan banyak tantangan lain termasuk tekanan regional yang kompleks (Rockefeller Foundation, 2015). Mengelola risiko bencana hidroklimatologi berarti mengidentifikasi bahaya, menurunkan kerentanan serta meningkatkan atau mengoptimalkan kapasitas kota yang ada. Sehingga pelaksanaan manajemen risiko dalam upaya mereduksi dampak bencana hidroklimatologis Kota Semarang dapat berdampak pada pembangunanan kota yang berketahanan (resilient city).

\section{ANALISA DAN MANAJEMEN RISIKO BENCANA HIDROKLIMATOLOGI UNTUK KETAHANAN KOTA DI SEMARANG}

Dalam Undang-Undang No. 24 Tahun 2007 menerangkan Bencana adalah peristiwa atau rangkaian peristiwa yang mengancam dan mengganggu kehidupan dan penghidupan masyarakat yang disebabkan, baik oleh faktor alam dan/atau faktor nonalam maupun faktor manusia sehingga mengakibatkan timbulnya korban jiwa manusia, kerusakan lingkungan, kerugian harta benda, dan dampak psikologis (Anonim, 2007). Bencana merupakan gabungan dari aspek ancaman bencana, kerentanan, dan kemampuan yang dipicu oleh suatu kejadiam. Keadaan bencana sangat bergantung dari tindakan manusia dalam menghadapi dan menganggulanginya (Wilson \& Arvanitakis, 2013). Pemahaman mengenai aspek kebencanaan juga mencakup terhadap parameter kelas risiko, Seperti skema R = H x V / C (Agrawal, 2018). R adalah Risiko (Risk), $\mathrm{H}$ adalah bahaya (Hazarrd), V adalah Kerentanan (Vulnarability) dan C adalah kapasitas (Capacity). Bencana terjadi jika risiko (risk) terdapat trigger serta terjadi akumulasi antara bahaya (hazard) bertemu dengan kerentanan (vulnerability) disaat yang sama parameter kapasitas rendah. Sebaliknya jika tingkat ancaman bahaya dan parameter kerentanan dapat direduksi dengan mitigasi 
(C) (2021) Sekolah Pascasarjana Universitas Airlangga, Indonesia

structural atau non-structural serta parameter

kapasitas ditingkatkan maka terjadinya risiko bencana menjadi kecil (Akter, 2019).

\subsection{Analisa Risiko Bencana Hidrometeorologi Kota Semarang}

Kota Semarang terletak antara garis $6^{\circ} 50^{\prime}-7^{\circ} 10^{\prime}$ Lintang Selatan dan garis $109^{\circ} 35-110^{\circ} 50^{\prime}$ Bujur Timur. Terletak 558 km sebelah Timur Jakarta dan $312 \mathrm{~km}$ sebelah Barat Surabaya. Dengan Letak Kota Semarang hampir berada ditengah bentangan panjang kepulauan Indonesia dari arah barat ke timur dengan temperatur udara rata-rata berkisar antara $27,50^{\circ} \mathrm{C}$ dengan temperatur terendah berkisar $24,20^{\circ} \mathrm{C}$ dan tertinggi $31,80^{\circ} \mathrm{C}$, serta mempunyai kelembaban udara rata-rata $79 \%$. Dengan panjang garis pantai meliputi 13,6 Km. Tercatat Luas wilayah Kota Semarang mencapai 373,70 $\mathrm{Km}^{2}$. Dari data yang dihimpun oleh BPBD Kota Semarang Total kejadian banjir dalam 5 tahun terakhir mencapai 874 kejadian, 321 kejadian kebakaran di pemukiman dan lahan, 296 kejadian tanah longsor, dan 29 kejadian putting beliung.

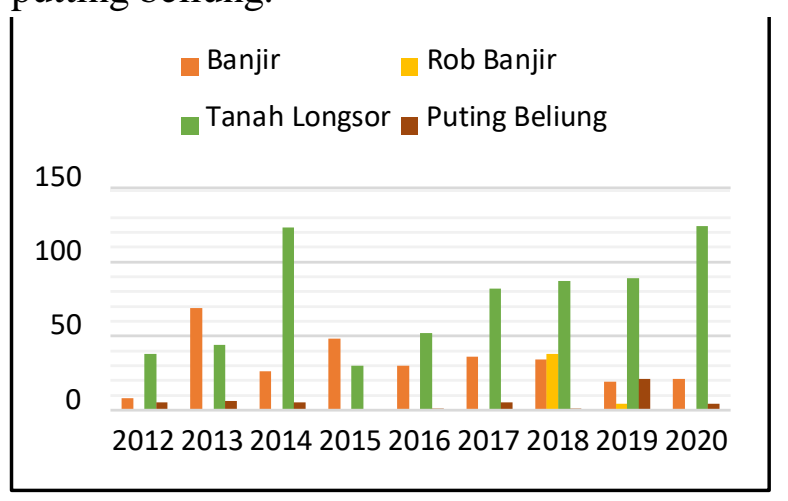

Grafik 1. Tren kejadian bencana Hidroklimatologi Kota Semarang tahun 2012-2020

Sumber: BPBD Kota Semarang (Data Kejadian Bencana Kota Semarang Tahun 2012-2020, 2020)

Jika ditinjau dari sejarah kondisi Kota Semarang kerentanan (Vulnarability) fisik dan lingkungan terus mengalami perubahan. Pada abad ke-6, garis pantai Semarang berada di daerah Bergota, sekitar $4 \mathrm{~km}$ dari garis pantai saat ini. Sedimentasi terus menerus dari daerah atas Semarang memperluas garis pantai lebih jauh, sehingga memperluas daerah pedalaman, yang tumbuh menjadi pemukiman di pesisir pantai. Tren kenaikan permukaan laut saat ini menghadirkan risiko banjir di masa depan untuk daerah ini. Daerah-daerah yang berpotensi rawan bencana banjir meliputi sebagian Kecamatan Tugu, Semarang Barat, Semarang Tengah, Semarang Utara dan Genuk.

BMKG mengklasifikasikan normal curah hujan menjadi 3 kategori, yaitu rendah $(0-100 \mathrm{~mm})$, menengah $(100-300 \mathrm{~mm})$, dan tinggi $(300-500 \mathrm{~mm})$. Curah hujan di Semarang tahun 2019 mencapai 181,83 mm. Hal ini mengindikasikan curah hujan di Semarang masuk dalam kategori menengah. Begitu juga factor klimatologi Kota Semarang yang ber iklim tropik basah karena dipengaruhi oleh angin muson barat dan muson timur. Akibatnya curah hujan di Kota Semarang mempunyai sebaran yang tidak merata yakni dengan total curah hujan ratarata $9.891 \mathrm{~mm}$ per tahun. Tidak berbeda dengan curah hujan khas pola di Indonesia, khususnya di Jawa, yang mengikuti pola angin muson SENW yang umum. Kelembaban relatif bulanan rata-rata berubah-ubah dari minimum $61 \%$ pada bulan September ke maksimum $83 \%$ pada bulan Januari.

Banjir dan rob merupakan ancaman bencana yang masih dihadapi oleh Kota Semarang dan diprioritaskan penanganannya. Letak kota Semarang yang berada dipinggir pantai Utara Jawa Tengah dan sebagian wilayah mengalami penurunan muka tanah menjadikan Kota Semarang sebagai langganan rob dan banjir. Kawasan yang masih mengalami banjir dan rob pada tahun 2016 masih seluas 5,02\% dari total luas Kota Semarang. Adapun dampak dari bencana tersebut antara lain adanya korban jiwa baik meninggal, luka-luka dan korban hilang. Selain itu dampak kerugian yang menyertai bencana adalah kerugian ekonomi yang ditaksir mencapai lebih dari 18 Triliyun Rupiah dan setiap tahun selalu bertambah. BPBD Kota Semarang telah merilis peta risiko bencana banjir berikut: 


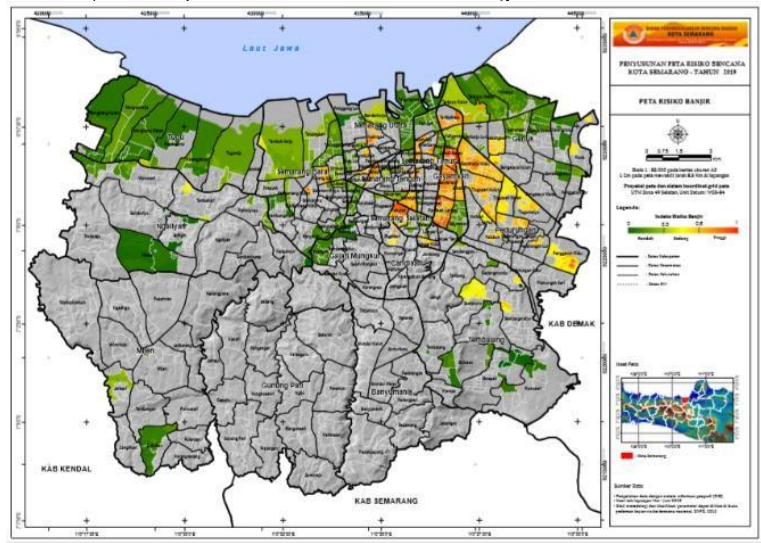

Gambar 1. Peta Risiko Bencana Banjir Kota Semarang Sumber: BPBD Kota Semarang

Setelah bencana banjir, tantangan bencana hidroklimatologis kedua adalah tanah longsor. Menurut BNPB dalam Panduan Pengenalan Karakteristik Bencana dan Upaya Mitigasinya di Indonesia menunjukan bahwa Jenis tanah, Kelerengan, Penggunaan lahan, Jenis batuan dan struktur geologi serta Hidrologi merupakan variable yang mempengaruhi tingkat kerawanan terjadinya tanah longsor. Sehingga perlu mengidentifikasi variabel tersebut dalam kaitan kejadian bencana tanah longsor sebagai bencana hidroklimatologis di Semarang.

Kota Semarang memiliki kontur miring yang terdiri dari daerah perbukitan, dataran rendah dan pantai. Daerah pantai $65,22 \%$ wilayahnya adalah dataran dengan kemiringan $25 \%$ dan $37,78 \%$ merupakan daerah perbukitan dengan kemiringan 15$40 \%$. Serta dipengaruhi oleh keadaan alam yang membentuk struktur geologi kota. Struktur geologi sebagian besar terdiri dari batuan beku yang mempunyai ciri khas yaitu dalam bentuk perbukitan, dataran rendah dan daerah pantai. Berdasarkan data topografi Kota Semarang yang tercantum dalam RTRW Kota Semarang 2011 - 2031, sebanyak $43,89 \%$ luasan wilayah Kota Semarang memiliki kelerengan yang berkisar $0-2 \%$. Hal ini karena sebagian besar Kota Semarang merupakan dataran rendah dengan ketinggian 2,45 mdpl.

Kondisi topografi Kota Semarang yang memiliki gerakan tanah tinggi merupakan daerah perbukitan. Sedangkan wilayah Kota Semarang yang berupa dataran rendah memiliki jenis tanah berupa struktur pelapukan, endapan, dan lanau yang dalam. Luas wiayah sebesar $373,70 \mathrm{~km} 2$. Berdasarkan pembagiannya Penggunaan Lahan atau Pemanfaatan lahan lebih banyak digunakan untuk jalan, pemukiman atau perumahan, bangunan, halaman, kawasan industri, tambak, empang atau embung dan persawahan.

\begin{tabular}{|c|c|c|}
\hline Pemanfaatan Lahan & $\begin{array}{c}\text { Persent } \\
\text { ase }\end{array}$ & $\begin{array}{l}\text { Luas } \\
(\mathrm{Ha})\end{array}$ \\
\hline Sawah & $10,14 \%$ & 37,90 \\
\hline Tegalan & $\begin{array}{r}20,31 \\
\%\end{array}$ & 75,89 \\
\hline Lading/Huma & $2 \%$ & 7,54 \\
\hline Perkebunan & $2,36 \%$ & 8,81 \\
\hline Ditanami Pohon & $3,60 \%$ & 13,45 \\
\hline $\begin{array}{l}\text { Padang Penggembalaan/ } \\
\text { rumput }\end{array}$ & $1,29 \%$ & 4,82 \\
\hline $\begin{array}{l}\text { Tambak/Kolam/Empang } \\
\text { dll }\end{array}$ & $\begin{array}{r}12,40 \\
\%\end{array}$ & 46,34 \\
\hline $\begin{array}{l}\text { Jalan/Pemukiman/Perkanto } \\
\text { ran/Sungai dll }\end{array}$ & $\begin{array}{r}47,55 \\
\%\end{array}$ & 177,68 \\
\hline $\begin{array}{l}\text { Sementara tidak } \\
\text { diusahakan }\end{array}$ & $0,35 \%$ & 1,29 \\
\hline Total & $\begin{array}{c}100,00 \\
\%\end{array}$ & 373,23 \\
\hline
\end{tabular}

Sumber: BPS Kota Semarang 2016

Kawasan rawan bencana ini merupakan kawasan yang mempunyai kerentanan terhadap bencana alam yaitu longsor dan gerakan tanah. Sebaran daerah yang rawan longsor diantaranya; Daerah gerakan tanah tersebar di Kecamatan Gunungpati dan Banyumanik. Hal ini didasarkan dari kondisi geologi kawasan ini berpotensi terjadi gerakan tanah. Daerah sesar aktif, yaitu daerah yang kondisi geologi kawasan ini memiliki patahan yang potensial untuk terjadi gerakan tanah. Berikut sebaran lokasinya; Di sepanjang Kecamatan Mijen dan Gunungpati yaitu melalui Kelurahan Sumurejo, Mangunsari, Gunungpati, Purwosari, Limbangan, dan Cangkiran b. Di sepanjang Kecamatan Banyumanik, yaitu melalui Kelurahan Jabungan, Padangsari, Plalangan, Sumurboto dan Tinjomoyo dan Kecamatan Gunungpati, yaitu melalui Kelurahan Sukorejo, Kalipancur dan Bambankerep. 


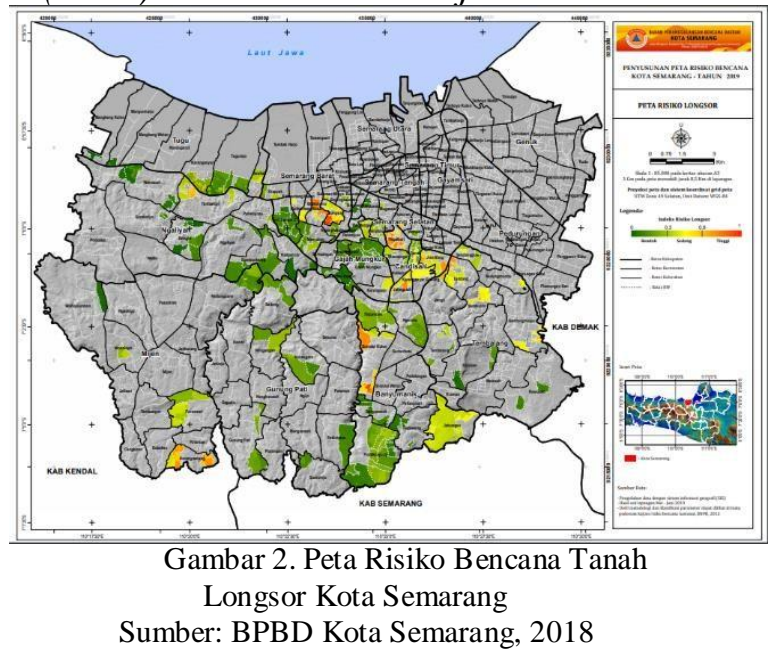

Selain itu kerentanan fisik dan lingkungan berikutnya ialah alasan Karena Kota Semarang juga menjadi Daerah Aliran Surngai (DAS) sehingga meningkatkan ancaman bahaya terjadinya banjir akibat meluapnya air sungai. Sungai yang melintasi Kota Semarang ialah Kali Garang yang bersumber dari Gunung Ungaran memiliki dua anak sungai, yakni Kali Kripik dan Kali Kreo. Daerah tangkapan Kali Garang mencapai $204 \mathrm{~km}^{2}$, termasuk daerah tangkapan Kali Kripik $93.4 \mathrm{~km}^{2}$ dan Kali Kreo $70 \mathrm{~km}^{2}$. Luas daerah genangan Kali Garang mencapai sekitar 145 ha. Hal ini pernah terjadi fenomena banjir di DAS Kali Garang pada bulan Januari tahun 1990 akibat luapan Kali Garang menimbulkan 47 korban jiwa, 151 rumah tergenang air. Ketinggian Genangan atau banjir mencapai $3 \mathrm{~m}$ dalam waktu 3 sampai 5 jam (Dewi Liesnoor, 2008).

Kondisi Hidrologi atau potensi air di Kota Semarang bersumber pada sungaisungai yang mengalir di Kota Semarang antara lain Kali Garang, Kali Pengkol, Kali Kreo, Kali Banjirkanal Timur, Kali Babon, Kali Sringin, Kali Kripik, Kali Dungadem dan lain sebagainya. Kali Garang bermata air dari gunung Ungaran. Alur sungainya mengalir ke arah utara hingga mencapai Pegandan tepatnya di Tugu Soeharto, bertemu dengan aliran Kali Kreo dan Kali Kripik. Kali Garang sebagai sungai utama pembentuk kota bawah yang mengalir membelah lembah-lembah Gunung Ungaran mengikuti alur yang berbelok-belok dengan aliran yang cukup deras. Setelah diadakan pengukuran debit Kali Garang mempunyai debit 53,0\% dari debit total dan kali Kreo $34,7 \%$ selanjutnya Kali Kripik 12,3\%. Oleh karena Kali Garang member suplai air cukup dominan bagi Kota Semarang. Kali Garang digunakan untuk memenuhi kebutuhan air minum warga Kota Semarang.

Kerentanan ekonomi akibat ancaman banjir pasang surut dan banjir bandang, sanitasi dan pengelolaan limbah, kemacetan, dan pengangguran menjadi kombinasi stress akut dan stress kronis. Sekitar lima persen dari populasi kota yang hidup dalam kemiskinan dianggap paling rentan terhadap masalah ini. Karena itu, perhatian khusus diperlukan untuk kelompok rentan tersebut.

Dampak yang ditimbulkan dari kombinasi kejadian bencana banjir, tanah longsor dan putting beliung diatas pada tahun 2015 terdapat 8 kejadian bencana, 2016 terjadi 32 kejadian, 2017 meningkat menjadi 86 kejadian hingga pada tahun 2018 menjadi 96 kejadian, dan tahun 2019 menjadi 151 kejadian. Kenaikan tren kejadian bencana di Kota Semarang tentu menimbulkan kerugian. Diantaranya ialah adanya korban jiwa, kerusakan rumah baik berat, sedang, ringan bahkan terendam. Kerugian ekonomi yang ditimbulkan juga cukup besar. Ditaksir kerugian ekonomi akibat bencana yang terjadi di kurun waktu 5 tahun tersebut sebanyak 13,8 Triliyun Rupiah.

Tebel 2. Dampak Akibat Bencana Kota Semarang

\begin{tabular}{cccccccc}
\hline \multirow{2}{*}{ Tahun } & \multicolumn{3}{c}{ Korban Jiwa } & \multicolumn{2}{c}{ Kerusakan } & $\begin{array}{c}\text { Kerugian } \\
\text { Ekonomi }\end{array}$ \\
\cline { 2 - 8 } & $\begin{array}{c}\text { Meninggall } \\
\text { Hilang }\end{array}$ & $\begin{array}{c}\text { Luka- } \\
\text { luka }\end{array}$ & Mengungsi & Berat & Sedang & Ringana & $\begin{array}{c}\text { Milvar } \\
(\text { Rp) }\end{array}$ \\
\hline 2015 & 0 & 0 & 11.926 & 3 & 14 & 1 & 2.338 \\
2016 & 2 & 2 & 3.582 & 8 & 21 & 17 & 3.084 \\
2017 & 3 & 2 & 1.367 & 16 & 15 & 40 & 3.270 \\
2018 & 0 & 3 & 81 & 27 & 27 & 26 & 5.125 \\
2019 & 4 & 11 & 14.366 & 22 & 99 & 91 & n/a \\
\hline
\end{tabular}

Sumber: BPBD Kota Semarang.

Parameter kerentanan social dalam menghadapi bencana ialah kepadatan penduduk dan kelompok rentan. Kepadatan penduduk yang cukup tinggi di daerah rawan bencana menyebabkan tingginya peluang timbulnya korban jiwa. Kelompok rentan 
merupakan parameter kedua dari kerentanan sosial yang terdiri dari empat variabel yaitu penduduk berdasarkan jenis kelamin, penduduk berdasarkan kelompok umur rentan, penduduk disabilitas dan penduduk miskin.

Kota Semarang yang merupakan Kota paling berkembang ke lima di Indonesia setelah Jakarta, Surabaya, Medan, dan Bandung. Berdasarkan hasil perhitungan proyeksi penduduk dari tahun 2010 hingga 2019 jumlah penduduk Kota Semarang terus meningkat. Dalam kurun 5 tahun peningkatan jumlah penduduk mencapai 100 ribu jiwa. Pada Tahun 2010 jumlah penduduk mencapai 1,4 juta jiwa. Tahun

2015 jumlah penduduk Kota Semarang tercatat sebesar 1.520.093 jiwa dengan pertumbuhan penduduk selama tahun 2015 sebesar 1,66 \%. Dengan sex ratio sebesar 0,96 . Menunjukkan jumlah penduduk lakilaki sebanyak 760.224 jiwa sedangkan jumlah penduduk perempuan sebanyak 759.869 jiwa. Dan tahun 2019 jumlah penduduk meningkat lagi menjadi 1,6 juta jiwa.

\begin{tabular}{|c|c|c|c|}
\hline \multirow{2}{*}{ Tahun } & \multicolumn{2}{|c|}{ Jumlah Penduduk } & \multirow{2}{*}{ Total } \\
\hline & Laki-laki & Perempuan & \\
\hline 2010 & 726.482 & 729.691 & 1.456 .173 \\
\hline 2015 & 760.224 & 759.869 & 1.520 .093 \\
\hline 2019 & 828.848 & 845.510 & 1.674 .358 \\
\hline
\end{tabular}

Jika melihat kelompok rentan seperti balita dan anak-anak mencapai 263.650 jiwa atau setara dengan $15,75 \%$ dari total jumlah penduduk. Sedangkan kelompok lanjut usia mencapai 103.667 jiwa atau setara dengan $6,19 \%$ dari total jumlah penduduk. Sedangkan jumlah penduduk miskin mencapai 71.969 jiwa atau $3.98 \%$. Sehingga tingkat kerentanan social Kota Semarang menghadapi bencana hidrometeorologi cukup tinggi karena mencapai 25,92\% dari total populasi.

Setelah mengurai faktor bahaya dan parameter kerentanan, perlu menjabarkan beberapa tingkat Kapasitas (Capacity) kota yang dapat dianalisis menggunakan beberapa parameter. parameter pertama ialah system peringatan dini dan kajian risiko bencana, kemudian parameter pendidikan kebencanaan, parameter pengurangan faktor risiko dasar, dan parameter kesiapsiagaan di seluruh lini. Kota semarang telah memiliki system peringatan dini dan kajian risiko bencana. Indikatornya adalah telah tersedianya sistem pemantauan dan pengarsipan data bencana serta terdapat data risiko bencana daerah. mengenai kajian risiko bencana tersedianya dokumen kajian risiko bencana seperti peta risiko bencana yang dapat diakses melalui web BPBD Kota Semarang secara lengkap.

\subsection{Manajemen risiko bencana hidroklimatologi Kota Semarang}

Banyak kerugian, baik korban jiwa maupun kerugian materi jika bencana banjir dan longsor terus berulang. Aktivitas ekonomi pun menjadi lumpuh akibat penanggulangan banjir yang masih mengalami kendala. Manajemen Risiko Bencana Hidrometeorologi Kota Semarang jika melihat keadaan dahulu saat setiap kali hujan, Kota Semarang selalu terendam banjir hingga seperti kolam renang. Namun, dengan berbagai upaya yang dilakukan, kini sebagian besar wilayah di Kota Semarang terbebas dari banjir. Langkah dan upaya yang dilakukan Pemkot Semarang ini mungkin bisa dijadikan contoh bagi pemerintah pusat ataupun daerah dalam menanggulangi masalah banjir.

Pemkot Semarang telah membangun sistem pengendali banjir seperti di luar negeri. Sistem tersebut dapat beroperasi untuk menyedot air di saluran apabila melebihi batas wajar. Selain itu, sistem ini dipantau selama 24 jam oleh petugas operator yang tersambung secara real time di situation room. Berkat upaya Pemkot Semarang tersebut, saat ini wilayah Kota Semarang 82,6 persen telah bebas dari banjir. Pekerjaan rumah Pemkot Semarang kini tinggal 17,4 persen. Pengoptimalan fungsi-fungsi pompa yang ada baik dari sistem pompanya, operasionalnya hingga petugas operatornya selama 24 jam yang harus siap. Kegiatan rutin untuk selalu 
(C) (2021) Sekolah Pascasariana Universitas Airlangga, Indonesia melalukan pengecekan Apabila ada hujan intensitas tinggi pompa sudah siap. Petugas di lapangan juga mengecek setiap saat apabila terdapat sampah yang kerap menyumbat saluran air hingga terbawa ke rumah pompa. Himbauan kepada masyarakat agar tidak membuang sampah sembarangan juga dilakukan. Karena biasanya yang jadi masalah itu sampah yang tersumbat. Peralatan yang dilakukan memang harus detail karena sumbatan cepat sekali walaupun sudah dibersihkan. Selain itu himbauan agar masyarakat tidak lagi membuang sampah di saluran atau sungai. Saat ini Kota Semarang melalui pengeolaan Dinas Pekerjaan Umum telah memiliki 46 rumah pompa yang tersebar di Kota Semarang, yang totalnya mampu menyedot air hingga mencapai 50.000 liter per detik. Sistemnya berada di command room yang memantau semua aktivitas pompa, supply BBM dan itu real time melalui smart infrastruktur PU. Pemetaan lokasi yang berpotensi banjir di Semarang, di antaranya daerah Semarang Timur, Kaligawe, Genuk, dan Muktiharjo.

Beberapa upaya antisipasi lainya adalah dengan terus melakukan pemetaan wilayah. Wilayah yang telah dipetakan kemudian tinggal secara kontinyu diupdate. Tidak menutup kemungkinan beberapa titik bencana baru muncul. Namun karena memang fokus saat ini yang masih ikut dalam penanganan covid-19 seperti melakukan penyemprotan disinfektan, bagi masker, menyalurkan bahan logistik dan lainnya pelaksanaan penanggulangan bencana banjir dan tanah longsor tidak maksimal.

Dalam mengelola pendidikan kebencanaan, parameter pengurangan faktor risiko dasar, dan parameter kesiapsiagaan di seluruh lini masih dapat ditingkatkan. Meskipun sudah terdapat peningkatan keterampilan dalam menangani keadaan darurat bencana di sekolah-sekolah. Indikator kesadaran masyarakat dan budaya siaga bencana sudah dilakukan strategi untuk membangun desa tangguh bencana. sudah diterapkan prosedur penilaian risiko bencana untuk pembangunan infrastruktur. Untuk rencana kebijakan pembangunan ekonomi belum ada kegiatan yang dilaksanakan untuk meningkatkan kapasitas di bidang ekonomi produksi. Sedangkan untuk rencana dan kebijakan pembangunan sosial sudah mulai digalakan dalam rangka mengurangi kerentanan bencana, seperti penanaman bakau dan mitigasi lainnya. Dalam perencanaan dan pengelolaan pemukiman penduduk dikarenakan belum sesuainya pembangunan kawasan di daerah huni yang ada dengan rencana tata guna lahan.

Untuk parameter Kesiapsiagaan di Seluruh Lini, Kota Semarang sudah memiliki prosedur untuk penanganan darurat bencana serta terdapat sistem untuk merekam informasi bencana di daerah. Tersedianya rencana kontijensi dan pelatihan tanggap darurat di kawasan rawan bencana sudah pernah dilaksanakan pelatihanpelatihan tentang evakuasi bencana dan kegiatan lainnya yang bertema pengurangan risiko bencana. Untuk indikator tersedianya finansial dan logistik tanggap darurat serta pemulihan pasca bencana memiliki anggaran khusus untuk penanganan bencana. Sedangkan tersedianya kebijakan, kapasitas teknis dan mekanisme penanganan darurat bencana, sudah terdapat relawan-relawan yang melaksanakan praktik penanganan darurat bencana Salah satu bentuk kesiapsiagaan masyarakat adalah pembentukan kelompok siaga kencana (KSB) yang berfungsi untuk mengorganisir masyarakat ketika menghadapi bencana. proses implementasi pembentukan dan penguatan KSB serta manfaat terbentuknya KSB mengalami peningkatan sebesar $37 \%$ karena masyarakat telah mendapat pelatihan kesiapsiagaan bencana.

\section{METODOLOGI PENELITIAN}

Penelitian ini menggunakan metode deskripsi kualitatif dengan pendekatan studi kasus. Subjek penelitian adalah stakeholder terkait dengan upaya manajemen risiko bencana hidroklimatologi di kota Semarang, yakni Badan Penanggulangan Bencana Daerah (BPBD) serta Badan Perencanaan 
dan Pembangunan Daerah (BAPPEDA)

Kota Semarang. Dengan durasi penelitian adalah 2 bulan dari bulan Mei sampai Juni 2020. Adapun data yang digunakan adalah data primer dan data sekunder yang diolah dari hasil wawancara, observasi, studi litelatur dan dokumentasi.

\section{PEMBAHASAN}

Asumsi bahwa ketahanan kota / perkotaan harus diperlakukan sebagai proses adaptasi positif dan aktif dari sistem perkotaan terhadap perubahan kondisi pembangunan, terhadap fenomena dan proses yang mungkin merupakan ancaman perkembangan yang kurang lebih dapat diprediksi, termasuk bencana alam. Penggunaan istilah 'kota tangguh' dipahami sebagai tahap akhir dari proses pengembangan ketahanan kota. Ketahanan Kota tidak hanya berarti sebagai kota yang dapat menahan tantangan saat ini dan beradaptasi, tetapi juga sebagai kota yang dapat berkembang lebih baik di masa depan. Dalam hal ini, semua elemen kota memiliki peran penting dalam menciptakan ketahanan kota. untuk bergerak bersama menuju Semarang yang tangguh, dengan tujuan akhir mewujudkan kesejahteraan seluruh masyarakat.

Guna mencapai tujuan tersebut Kota Semarang tergabung menjadi bagian dari 100 resilient ciries (100 RC), yakni kerjasama kota-kota di dunia untuk menyusun strategi menjadi kota berketahanan. Keterlibatan semarang dalam 100 RC adalah bentuk komitmen semarang menjadi kota yang setiap elemennya memiliki kapasitas unggul dalam menghadapi berbagai masalah perkotaan. Perlu diperhatikan adalah bagaimana upaya tersebut menjadi solusi bagi apapun masalah yang mengancam, misalnya abrasi, kenaikan muka air laut, land subsidence, dan pencemaran. Masyarakat menjadi bagian dari konsep, pelaksana dan control pengawasan agar upaya berjalan dengan baik. Memastikan setiap gerakan dalam urban resilience menjadi gerakan bersama di jalan kebenaran.
Jika warga melihat kota sebagai bagian dari dirinya mereka akan mencari cara agar survive dan bisa berkembang dikemudian hari. Kalau diperhatikan warga yang hidup di daerah rawan bencana dan factor yang merusak lainya tentu mereka sudah memiliki cara-cara bertahan. Tahan bukan hanya soal fisik tapi juga non-fisik seperti spirit, etos kerja dan semangat agar bertahan dan berusaha menjadi komunitas yang lebih baik. Warga Dusun Tapak, Kelurahan Tugurejo misalnya yang aktif merahabilitasi kawasan pesisir dengan merostorasi hutan mangrove.

Partisipasi aktif masyarakat sangat sentral peranya dalam membangun, merawat dan memajukan Kota Semarang. Seperti halnya tantangan kota besar lainya semarang juga memiliki masalah pemukiman, sanitasi, kemacetan dan kemiskinan. Ditambah dengan letak kota semarang yang ada di pesisir memiliki tantangan banjir dan banjir rob. Yang pernah terjadi sekitar tahun 2013 kota semarang dikepung banjir setinggi satu meter dan banjir bandang di wilayah barat setinggi 1,5 m mengakibatkan 4 kelurahan tergenang.

Upaya normalisasi banjir kanal barat sepanjang 9,2 km berhasil mengurangi risiko banjir sekitar $36 \%$ di wilayah barat. Sungai yang telah bersih dapat dimanafaatkan menjadi ruang terbuka bagi masyarakat semarang. Kesiapan warga kota semarang dalam menghadapi bencana juga terus ditingkatkan. Salah satunya dengan membentuk kelompok siaga bencana (KSB) yang membantu mereka menyiapkan diri mengurangi dampak terhadap bencana yang akan datang. Seperti halnya di kampong wonosari yang merupakan daerah aliran sungai (DAS) Bringin yang rawan banjir. Warga raajin berkoordinasi, baik antar warga maupun dengan pemerintah melalui BPBD Kota Semarang. Dampaknya dapat terlihat dari setelah KSB terbentuk jika terjadi banjir sudah tidak ada korban jiwa, sebaliknya pada tahun 2010 saat terjadi banjir tercatat 6 orang meninggal karena hanyut terbawa arus sungai saat banjir. 
Faktor-faktor yang terkait dengan infrastruktur dan kebutuhan dasar lebih sering disebutkan dan dianggap paling penting. Namun, kinerja kota pada infrastruktur dan kebutuhan itu dianggap lemah. Tampaknya ada kurang perhatian publik terhadap kepemimpinan, strategi, dan dimensi sosial ekonomi, yang dikonfirmasi oleh penilaian ketahanan. Selain itu, analisis yang lebih teliti menemukan masalah terkait dengan perencanaan dan manajemen yang dibungkam antara lembaga kota dan pemerintah provinsi, kurangnya penyebaran informasi kepada masyarakat dan tingkat pendidikan yang rendah, yang tercermin dalam kapasitas kota yang terbatas.

Dalam data Indeks Risiko Bencana Indonesia (IRBI) 2018, Kota Semarang berada di urutan 400 dari $514 \mathrm{Kab} /$ Kota seluruh Indonesia dengan skor ancaman 120,75 yang artinya diklasifikasikan sebagai wilayah dengan risiko bencana sedang. Skor ini menunjukan hasil perhitungan multi ancaman di seluruh wilayah Indonesia. Kota Semarang berhasil memperbaiki skor indeks risiko bencananya dari tahun 2015 dengan skor 183,60 (Tinggi) turun di tahun 2016 sampai 2017dengan skor 124,72 (Sedang) dan kembali turun di tahun 2018 dengan skor 120,75 (Sedang).

Setiap upaya untuk meningkatkan ketahanan kota dalam menghadapi guncangan dan tekanan yang meningkat perlu didukung dengan kapasitas yang sangat baik. Kapasitas memiliki fungsi penting dalam meningkatkan ketahanan. Oleh karena itu, strategi ketahanan kota agar dapat memberi banyak perhatian pada pembangunan kapasitas, khususnya pembangunan kapasitas untuk pemerintah, masyarakat dan lembaga untuk meningkatkan pemberdayaan dan produktivitas. Pandangan holistik juga melihat hubungan masalah dan fungsi yang dirasakan. Mengenai masa depan, bahwa dengan Dokumen Strategi Ketahanan Kota Semarang, bersama dengan semua tantangannya, dapat menjadi kota yang lebih tangguh dan berkembang menjadi kota yang modern dan berkelanjutan.

\section{KESIMPULAN DAN SARAN}

Banjir dan rob merupakan ancaman bencana yang masih dihadapi oleh Kota Semarang dan diprioritaskan penanganannya dengan upaya mitigasi structural dan nonstructural. Infrastruktur dan system pengendali banjir telah dibangun di beberapa titik rawan banir. Berkat upaya Pemkot Semarang tersebut, saat ini wilayah Kota Semarang 82,6 persen telah bebas dari banjir

Untuk upaya peningkatan kapasitas kota (mitigasi non-struktural) dilakukan pendidikan kebencanaan, parameter pengurangan faktor risiko dasar, dan parameter kesiapsiagaan di seluruh lini. Kemudian kebijakan, kapasitas teknis dan mekanisme penanganan darurat bencana, melalui relawan-relawan yang melaksanakan praktik penanganan darurat bencana. Salah satu bentuk kesiapsiagaan masyarakat adalah pembentukan kelompok siaga kencana (KSB) yang berfungsi untuk mengorganisir masyarakat ketika menghadapi bencana. proses implementasi pembentukan dan penguatan KSB serta manfaat terbentuknya KSB mengalami peningkatan sebesar $37 \%$ karena masyarakat telah mendapat pelatihan kesiapsiagaan bencana.

Keterlibatan semarang dalam $100 \mathrm{RC}$ adalah bentuk komitmen semarang menjadi kota yang setiap elemennya memiliki kapasitas unggul dalam menghadapi berbagai masalah perkotaan. Perlu diperhatikan adalah bagaimana upaya tersebut menjadi solusi bagi apapun masalah yang mengancam. Kota Semarang berhasil memperbaiki skor indeks risiko bencananya dari tahun 2015 dengan skor 183,60 (Tinggi) turun di tahun 2016 sampai 2017dengan skor 124,72 (Sedang) dan kembali turun di tahun 2018 dengan skor 120,75 (Sedang). Oleh karena itu, strategi ketahanan kota agar dapat memberi banyak perhatian pada pembangunan kapasitas, khususnya pembangunan kapasitas untuk pemerintah, masyarakat dan lembaga untuk meningkatkan pemberdayaan dan produktivitas 


\section{UCAPAN TERIMAKASIH}

Penulis ingin mengucapkan terimakasih kepada semua pihak yang telah membantu terlaksananya penelitian ini. Pertama kepada Direktur sekolah pascasarjana dan Pimpinan Prodi Manajemen Bencana yang telah memberi kesempatan dalam penulisan penelitian ini. Kedua kepada dosen pembimbing Prof. Subagyo Adam dan Dr. Moses Glorino Rumambo Pandin dalam pemberian masukan, arahan, kritik dan saran yang membangun sehingga penulis dapat menyelesaikan penelitian ini. Ketiga dan yang utama kepada seluruh stakeholder yang terlibat dalam upaya manajemen bencana di Kota Semarang oleh BPBD Kota Semarang dan BAPPEDA Kota Semarang yang telah menjadi key person dalam selesainya penelitian ini.

\section{DAFTAR PUSTAKA}

Agrawal, N. (2018). Natural Disasters and Risk Management in Canada. In International Perspectives on Natural Disasters: Occurrence, Mitigation, and Consequences.

Akbar, I., Poerbo, H. W., \& Soedarsono, W. K. (2019). Adaptive Urban Design Principles for Land Subsidence and Sea Level Rise in Coastal Area of Tambak Lorok, Semarang. IOP Conference Series: Earth and Environmental Science. https://doi.org/10.1088/17551315/273/1/012005

Akter, S. (2019). Big data and disaster management: a systematic review and agenda for future research. Annals of Operations Research, 283((1-2)), 939959.

Anonim. (2007). UU no. 24 tahun 2007 tentang Penanggulangan Bencana. Pemerintah Republik Indonesia.

Bappeda Kota Semarang. (2011). Rencana Tata Ruang Wilayah Kota Semarang Tahun 2011-2031. Bappeda Kota Semarang.

Bauer, S. (2014). United Nations Environment Programme. In Essential Concepts of Global Environmental
Governance.

https://doi.org/10.4324/978020355356 5

BNPB. (2018). Indeks Risiko Bencana Indonesia. BNPB.

Data Kejadian Bencana Kota Semarang tahun 2012-2020. (2020). BPBD Kota Semarang.

http://bpbd.semarangkota.go.id/pages/d ata-bencana

Hijioka, Y., Erda, L., Pereira, J. J., Corlett, R. T., Cui, X., Insarov, G. E., Lasco, R. D., Lindgren, E., \& Surjan, A. (2014).

2014: Asia. Climate Change 2014: Impacts, Adaptation, and Vulnerability. Part B: Regional Aspects. Contribution of Working Group II to the Fifth Assessment Report of the Intergovernmental Panel on Climate Change.

IOM. (2020). World Migration Report 2020. In International Organisation for Migration.

Lal, R., Delgado, J. A., Groffman, P. M., Millar, N., Dell, C., \& Rotz, A. (2011). Management to mitigate and adapt to climate change. In Journal of Soil and Water Conservation. https://doi.org/10.2489/jswc.66.4.276

Narieswari, L., Sitorus, S. R. P., Hardjomidjojo, H., \& Putri, E. I. K. (2019). Multi-dimensions urban resilience index for sustainable city. IOP Conference Series: Earth and Environmental Science. https://doi.org/10.1088/17551315/399/1/012020

Roberts, I., \& Yano, N. (2010). As Ranks of "Environmental Refugees" Swell Worldwide, Calls Grow for Better Definition, Recognition, Support. In United Nations University.

Rockefeller Foundation. (2015). 100 Resilient Cities. 100 Resilient Cities.

Wilson, M. J., \& Arvanitakis, J. (2013). The Resilience Complex. M/C Journal. https://doi.org/10.5204/mcj.741

\section{APPENDIX}

